\title{
New contraceptive developments
}

Population Council

Follow this and additional works at: https://knowledgecommons.popcouncil.org/ series_newsletters_momentum How does access to this work benefit you? Let us know!

\section{Recommended Citation}

"New contraceptive developments," Momentum newsletter. New York: Population Council, 2008. 

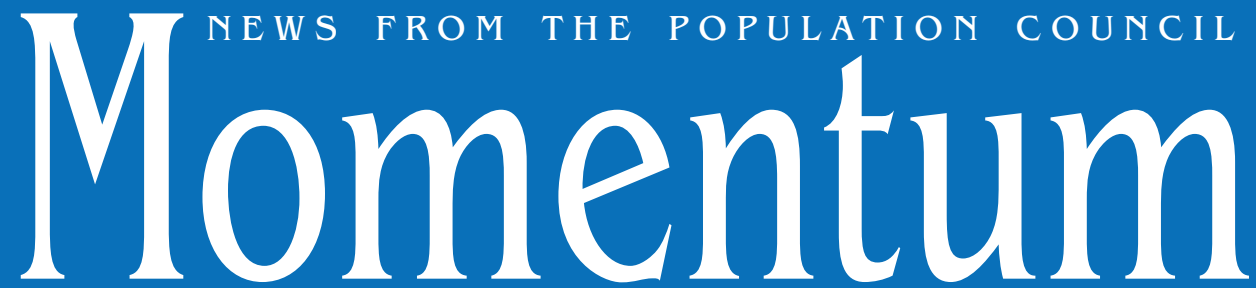

DECEMBER 2008

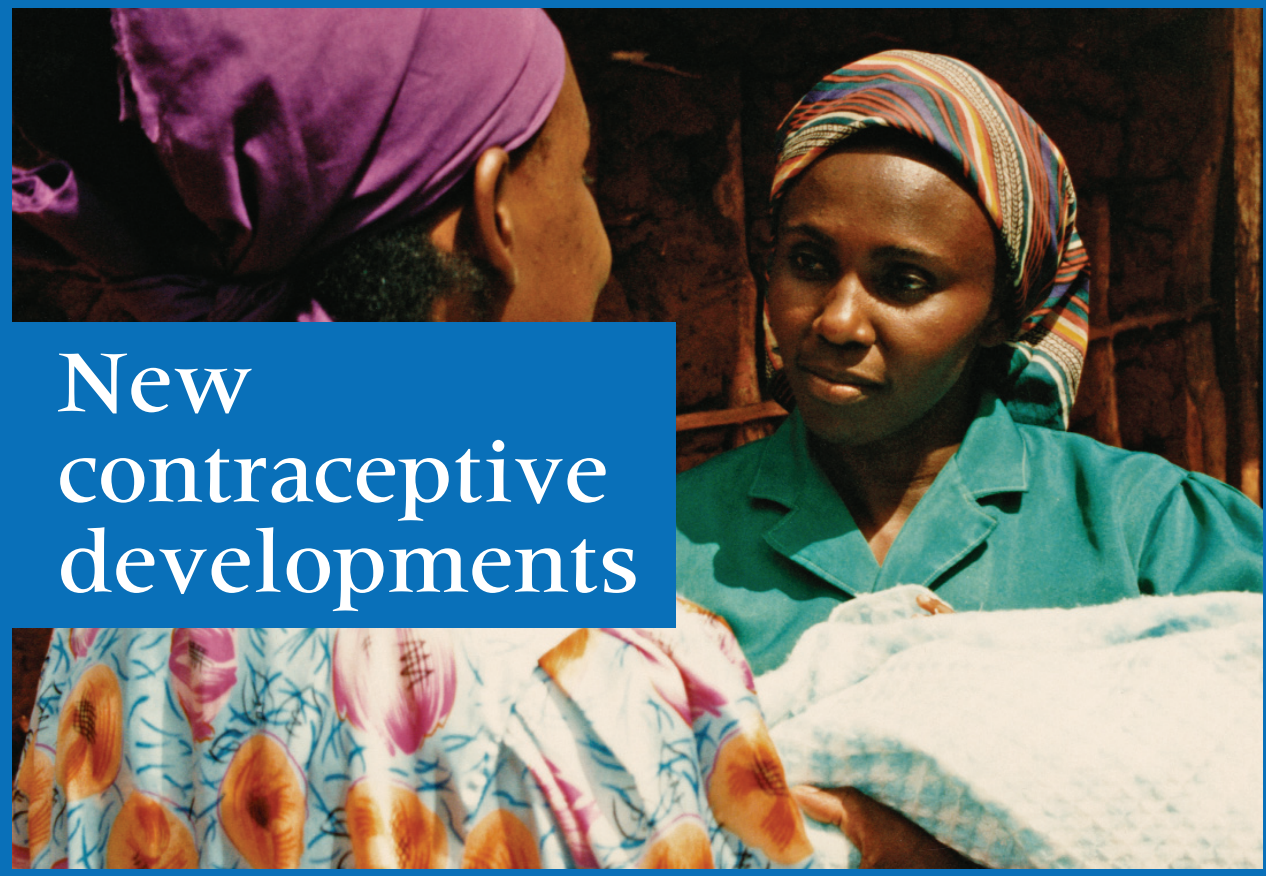

A health worker counsels a Kenyan woman on contraceptive options after the birth of her first child.

IN THIS ISSUE:

ONE RING FOR ONE YEAR OF CONTRACEPTION

A COMPREHENSIVE APPROACH TO CONTRACEPTION CONTRACEPTIVE CHOICES FOR DIVERSE POPULATIONS CREATING MORE CONTRACEPTIVE OPTIONS FOR MEN SEEKING A WINNING COMBINATION PROFILE: A CONVERSATION WITH DR. RENSHAN GE PROFILE: DONOR KATY STOKES 


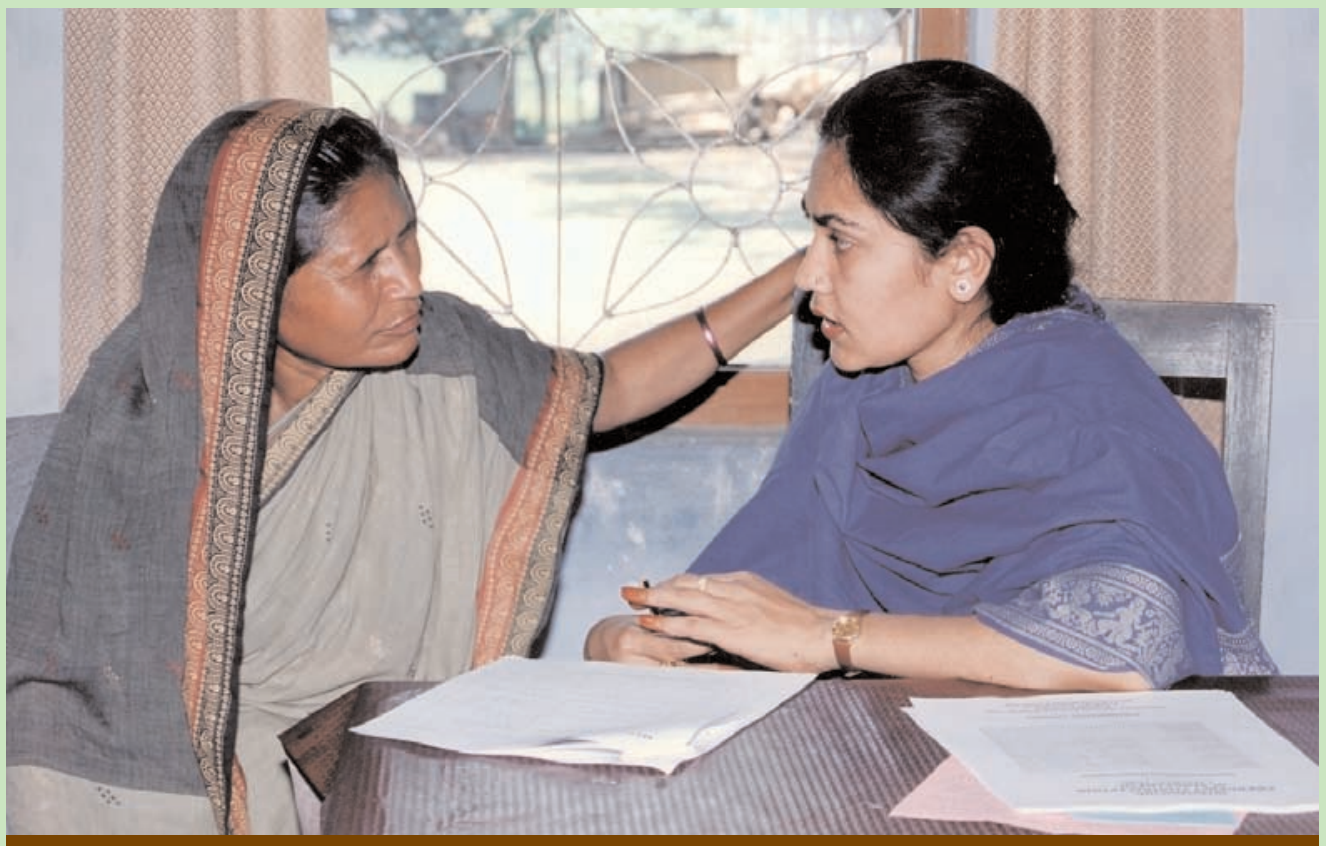

\section{CONSIDER THESE FIGURES:}

Number of women in developing countries using no method or only traditional methods of contraception: 201 million $^{1}$

Estimated annual cost of providing contraceptive services to those women: $\$ 3.9$ billion $^{2}$

Percentage of married women aged 15 to 49 in sub-Saharan Africa not using any contraceptive method: $77^{3}$

Estimated annual number of women worldwide who have an abortion: 46 million $^{4}$

Number of unintended pregnancies globally between Jan. 1995 and Dec. 2000: 338 million $^{5}$

Percentage of American women who switched contraceptive methods in less than a year, suggesting dissatisfaction: $24^{6}$

Percentage of women surveyed in South Africa who thought a male contraceptive pill was a good idea: $90^{7}$

Percentage of contraceptive research budgets allocated to male methods: $8^{8}$

Number of women globally who have used long-term, reversible contraceptives developed by the Population Council: more than 100 million ${ }^{9}$

Number of American women who have received free Mirena IUSs as a result of the Population Council's agreement with the manufacturer: over $50,000^{10}$
NOT ONLY CAN UNINTENDED pregnancy and birth be lethal to mother and child, they often trap women in a cycle of poverty in which they are unable to educate or support themselves and to provide for a baby.

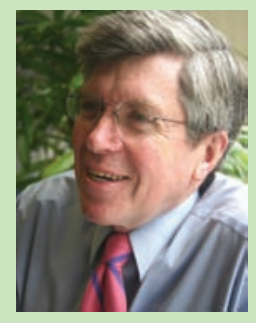
Modern contraceptives are available in most countries, but with only a few options the rate of unplanned pregnancy remains stubbornly high. This unmet need for contraception puts women's lives at risk and keeps women and children in a state of poverty.

At the Council, clinical research is driven by the principle that no one method of contraception will fit everyone's needs. An IUD might be ideal for a mother of three living in Mexico City, while a young woman in rural Kenya, without reliable access to a medical facility, may require a different method. We draw on biomedical and social science research to create new contraceptives that meet different women's needs while maintaining the high standards for safety and effectiveness for which Council products are known. Once we've developed a safe and reliable product, we work hard to see that it's made available in developing countries at an affordable price.

This issue of Momentum highlights our most recent solutions to meeting the unmet need for contraception. Our pioneering work on male contraception (see page 8 ) challenges the idea that women are solely responsible for controlling fertility. Our new vaginal ring (see page 2) will, we hope, make ring technology a viable option for women in developing countries. The improvements we are making to contraceptive distribution in resource-poor areas (see page 4) help to ensure that the right products reach the people who need them.

Contraceptives save lives and give people a chance to provide for themselves, their families, and their futures. Your contributions make this empowerment possible. Please support us in developing contraceptive solutions for the people who need them most.

Sincerely,

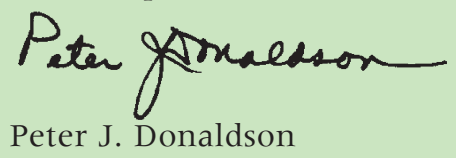




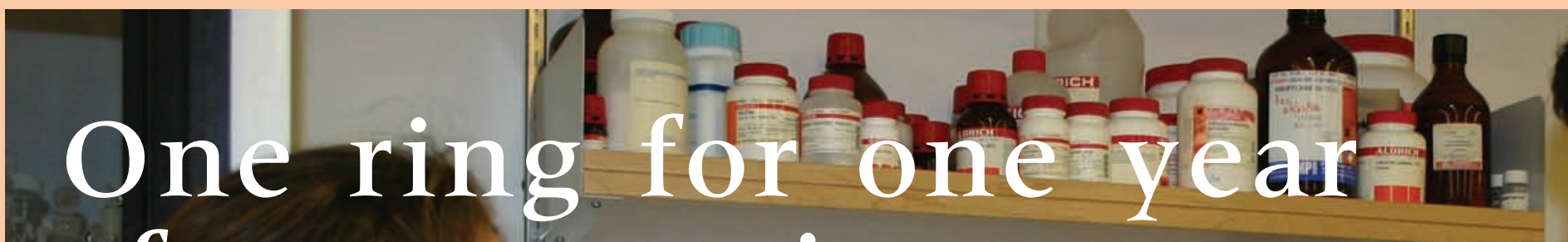
of contraception
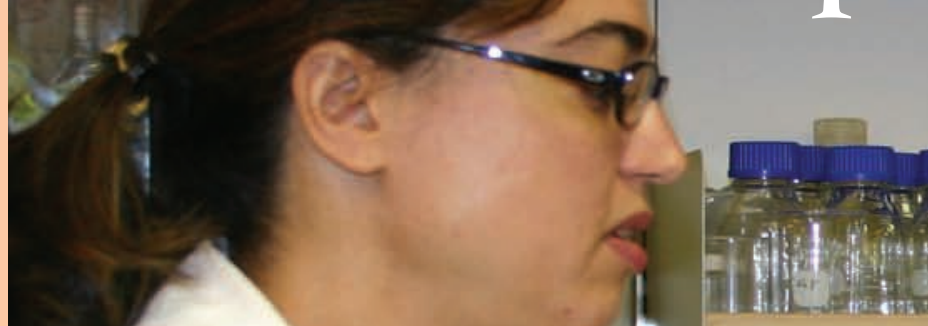

NEW LOW-COST, EASY-TO-USE CONTRACEPTIVE METHODS are critical to meeting the family planning needs of the world's most vulnerable women. Current methods require regular access to either a pharmacy or health care provider. The Council has developed a new contraceptive vaginal ring that may be especially attractive to women who have limited access to health facilities.
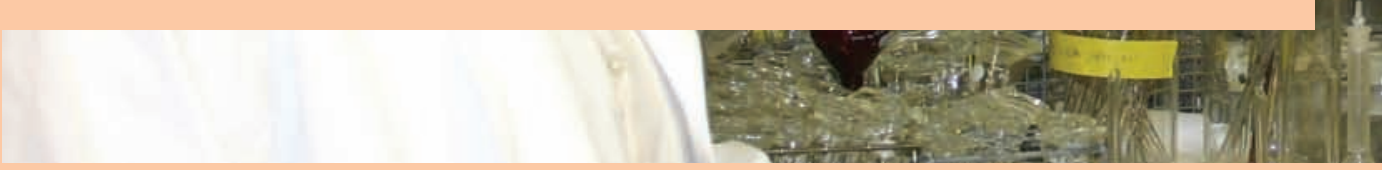

THE PROBLEM Women living in rural or resource-poor areas often cannot obtain modern methods of birth control. Many rural communities lack well-stocked pharmacies where women can dependably get pills or patches. Longer-term methods such as an IUD or implant can be too difficult to obtain, since these options require a trained medical worker to provide or remove the device. These women need a new method of contraception that they control and that does not depend on regular access to a pharmacy or medical provider.

THE PROGRESS The Council has developed a new contraceptive vaginal ring that is particularly suited to women in resource-poor settings and could also be ideal for many women in more developed areas. A woman can insert and remove the ring without assistance from a health care provider, and the same ring can be used for a full year, eliminating the need for regular access to a pharmacy and reduc-
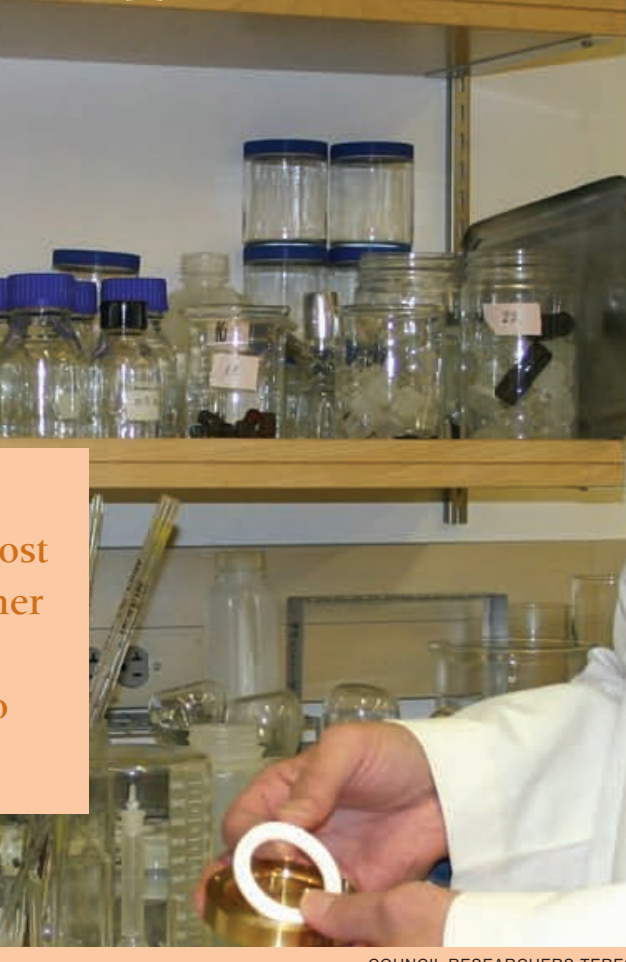

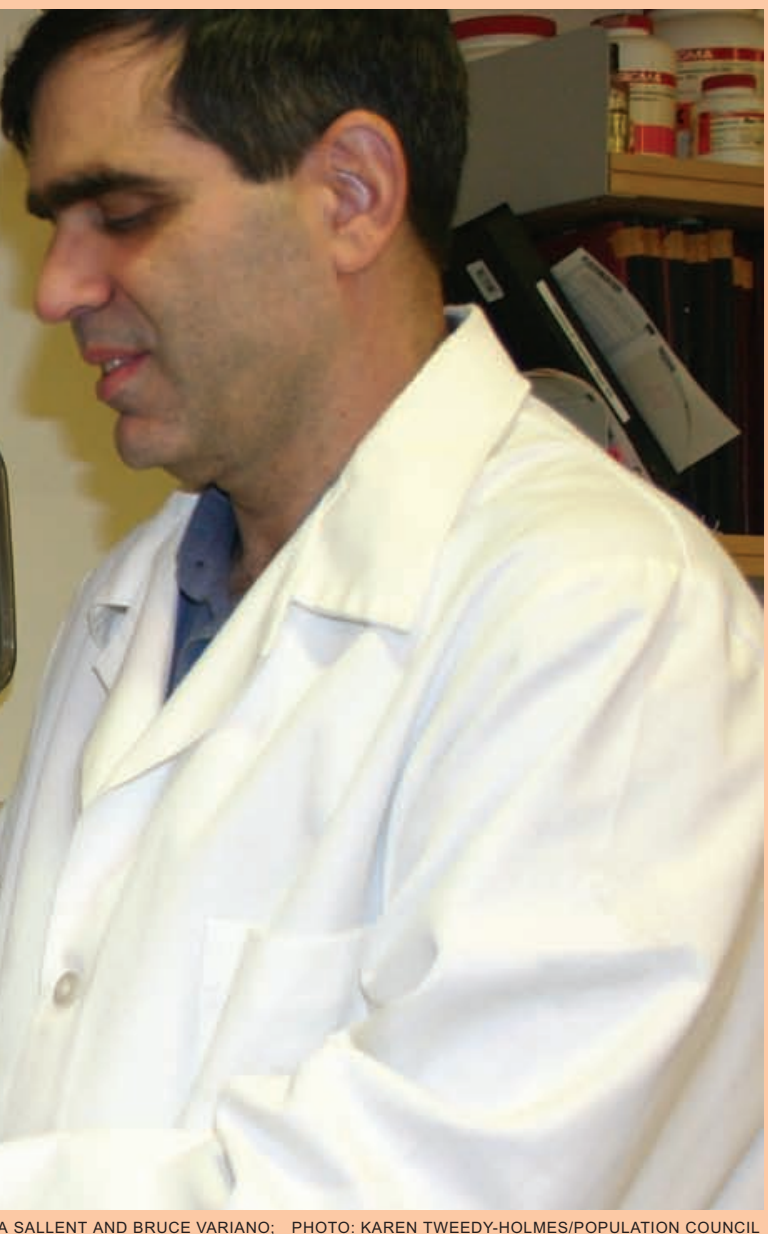

COUNCIL RESEARCHERS TERESA

ing distribution costs. As an added benefit, many women may find the ring especially easy to use since, unlike oral contraceptives, no daily routine is required. Women leave the ring in for three weeks, take it out for one week of menstruation, and then reinsert the ring for three weeks. Unlike the one-month vaginal ring currently on the market in the US, the Council ring does not need to be refrigerated before use, making the ring particularly suited for distribution in the developing world. Clinical trials of the new ring will end in mid-2009. Preliminary results indicate that the ring is as safe as other contraceptives on the market, effective, easy to use and that most participants prefer the ring to their current method of birth control.

THE SOLUTION Women in resource-poor settings are especially vulnerable to the consequences of unwanted pregnancy. The Council's contraceptive vaginal ring will be an important new option for these women. 


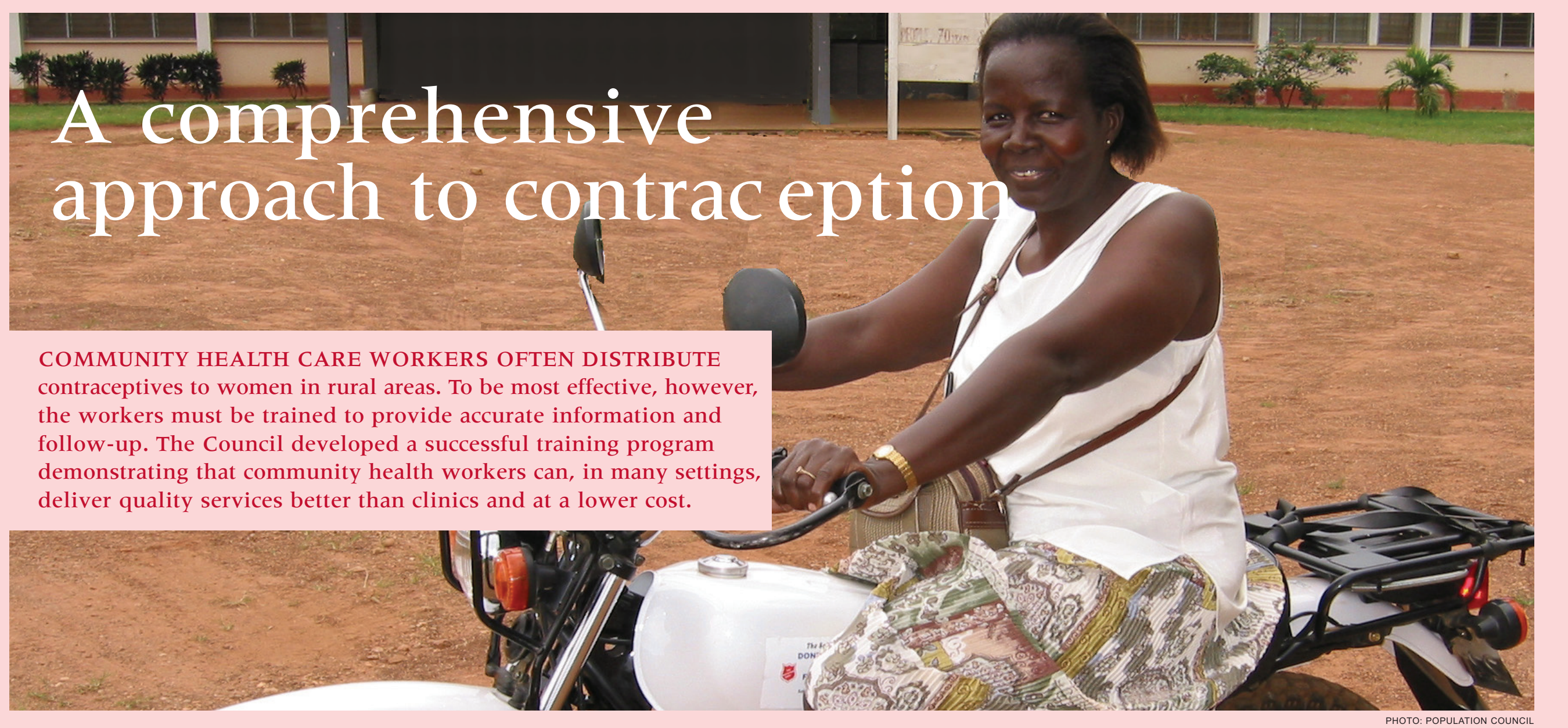

THE PROBLEM Access to quality medical care, or medicine of any kind, is especially difficult in remote rural areas of the developing world, where reaching the nearest health center or pharmacy may mean walking for many hours. Community health workers may represent a low-cost alternative for delivering basic health services, including contraceptives. In order to be most effective, however, these workers need appropriate training.
THE PROGRESS The Council, together with governments and partner organizations, developed a community health worker training program to address the need for accurate information and confidential access to contraceptive services. In Senegal, Council research illustrated how trained community health workers could increase access to family planning services more effectively than investing in clinic-based family planning programs or training a new cadre of reproductive health specialists. After completing the Council's training program, community health workers provided excellent quality of care, including informing clients about available contraceptive choices, providing current and accurate information on benefits and drawbacks, and offering clients a chance to change methods if necessary. Moreover, contraceptive distribution using community health workers is less expensive than hiring and training new out- reach workers or starting a new program at a clinic. In addition, the Council has proven that community-based contraceptive distribution increases the acceptability of family planning, especially in traditional societies.

THE SOLUTION Training community health care workers to provide family planning services can expand contraceptive access to populations living in remote rural areas at relatively low cost. 


\section{Contraceptive choices for diverse populations}

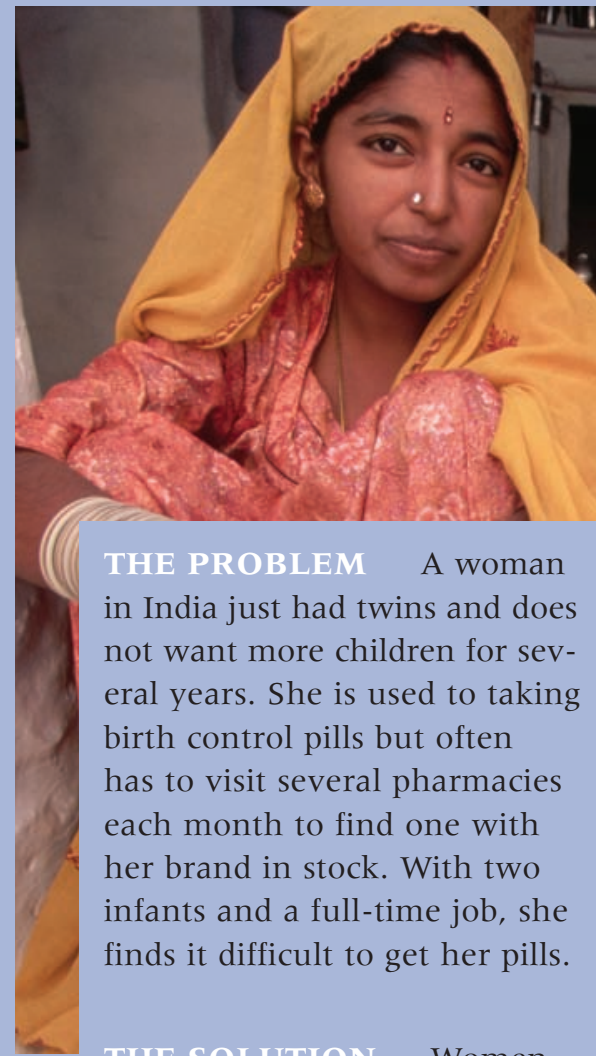

THE SOLUTION Women who want to delay pregnancy for several years can use an IUD or subdermal implant to provide five to ten years of completely reversible contraception, without the need to take a daily pill. The Council has developed three IUDs and two generations of implants, Norplant ${ }^{\circledR}$ and Jadelle $^{\oplus}$, to give women more options for long-term, lowmaintenance contraception.

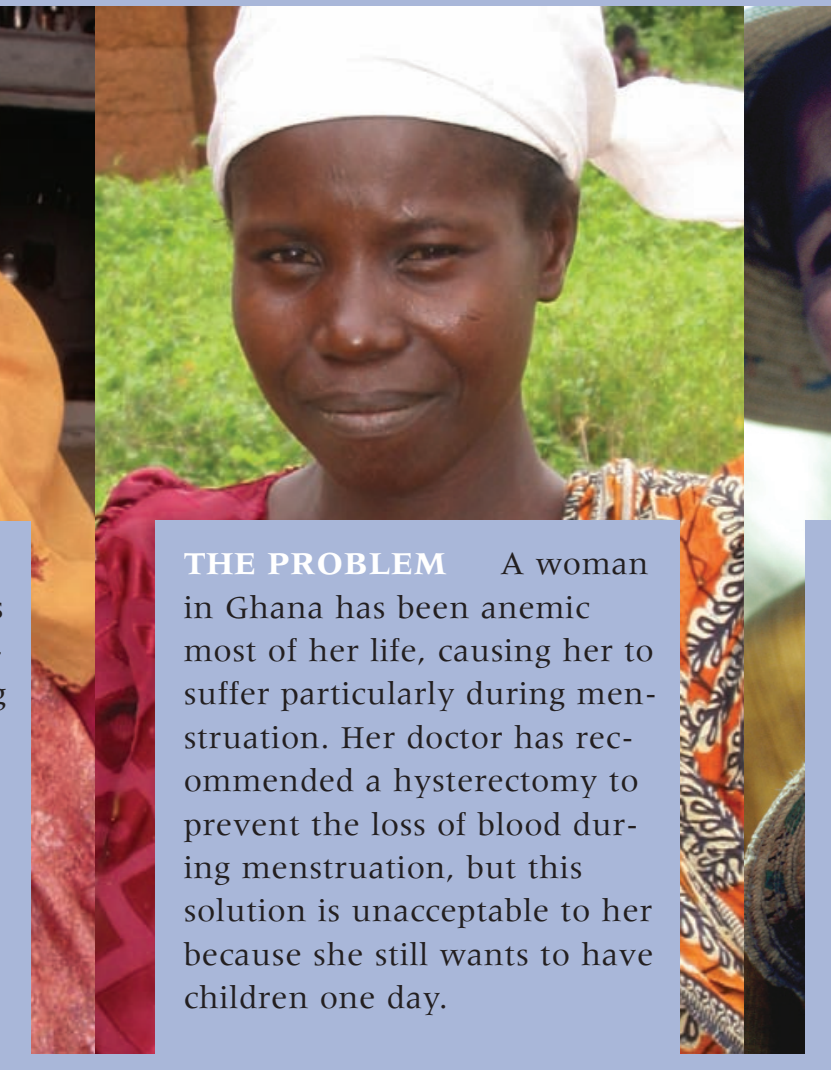

THE SOLUTION Mirena ${ }^{\oplus}$, a Council-developed intrauterine system (IUS), provides up to five years of contraception with a low dose of hormone and has the added benefit of greatly reducing menstrual bleeding, sometimes by up to 90 percent.

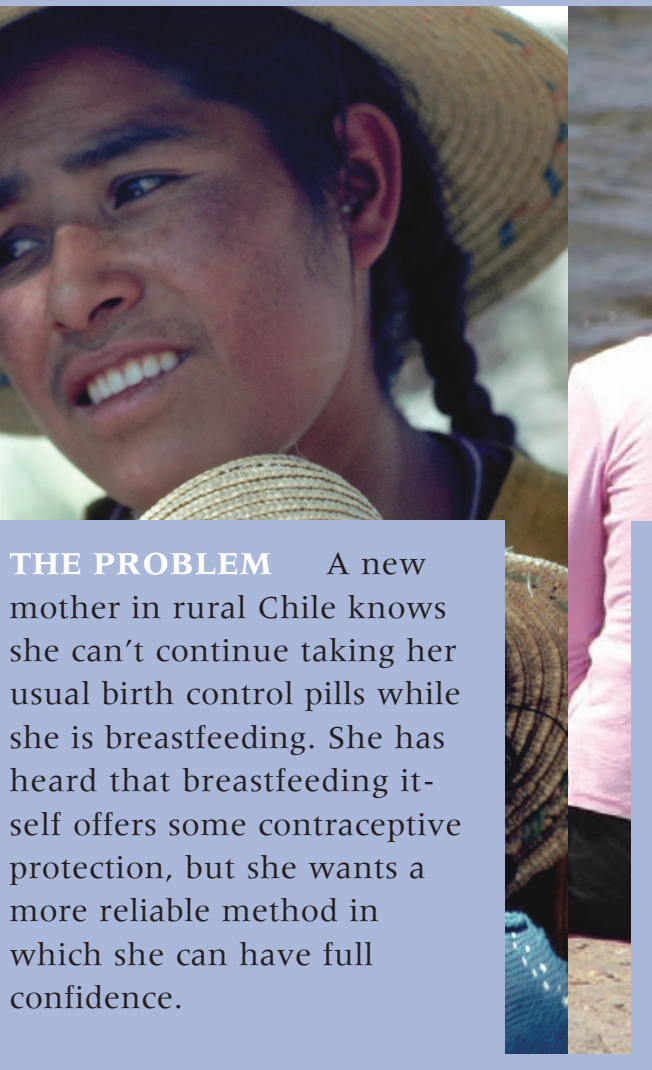

THE SOLUTION The Council's progesterone vaginal ring provides contraception during breastfeeding. Vaginal rings require no dayto-day maintenance and, unlike some other hormones, progesterone is safe to use while lactating.

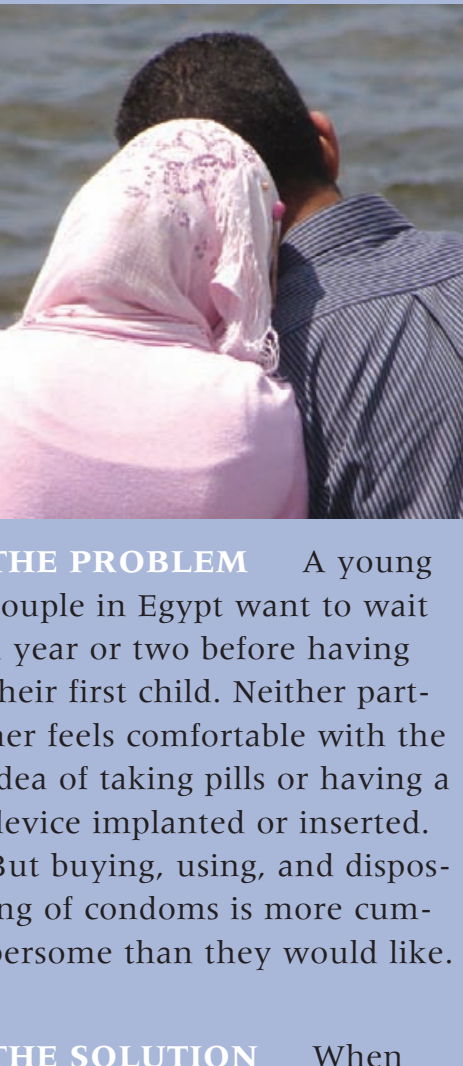
applied to the skin, Nestorone ${ }^{\oplus}$, a Council-developed synthetic progestin, may provide safe, reversible suppression of ovulation. The Council is working with a small pharmaceutical company to test whether a daily application of a Nestoronebased gel can prevent ovulation and pregnancy. 
Creating more con traceptive options for men

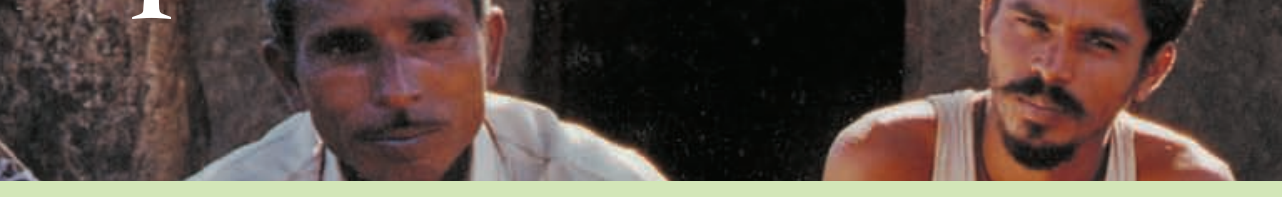

PROVIDING MEN WITH CONTRACEPTIVE CHOICES IS AN important but neglected approach to reducing unwanted pregnancy. Although men in both developed and developing countries have indicated they would like more choices for contraception, the Council is one of very few organizations committed to male contraceptive development.

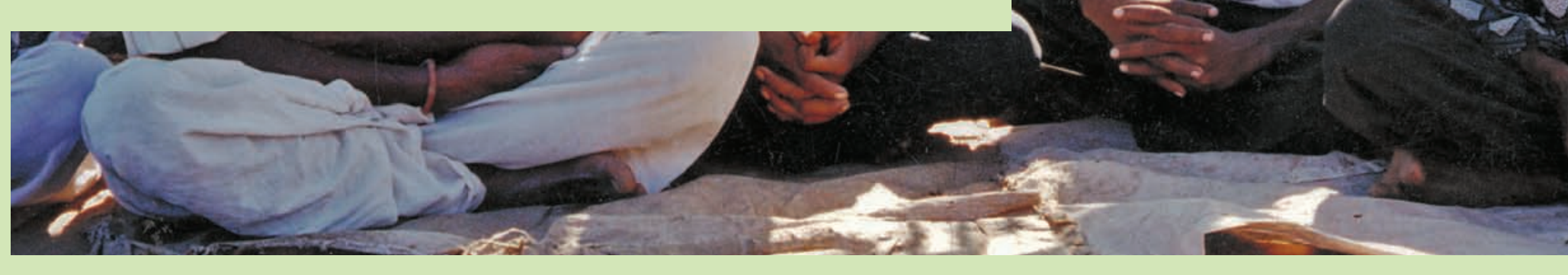

THE PROBLEM Surveys indicate a demand for more contraceptive choices for men, yet very few companies or organizations are researching new methods. The only two choices for men today are a vasectomy, which is expensive and permanent, and condoms, which are not widely used consistently.

THE PROGRESS Council researchers are investigating several promising male contraceptive options. One substance that shows 8 great potential is Adjudin, a non- hormonal compound derived from an anti-cancer drug. Adjudin has a demonstrated, reversible ability to stop sperm maturation in animals. Safety studies are needed before large-scale studies in humans begin.

The Council is also conducting promising research with a synthetic male hormone called MENT ${ }^{\oplus}$, which suppresses testosterone and sperm production while simultaneously maintaining male sex characteristics such as sex drive and muscle mass. Council researchers are conducting clinical trials that test dosages and combinations of MENT with other hormones. Because it is ten times more potent than testosterone, MENT can be administered in small doses, making it a candidate for use in a long-acting implant that might be inserted under the skin of the upper arm. (The Council has already developed similar implants for women.) One trial using MENT implants showed a significantly reduced sperm count in male volunteers. Sperm counts returned to normal after the implants were removed.
Additional basic research focuses on how sperm develop the ability to fertilize eggs, what critical factors affect sperm production and mobility, and the genetic mechanisms of action of male sex hormones.

THE SOLUTION Men can help reduce unwanted pregnancy if they are provided with easy-to-use, reversible contraception. With additional investment in research, MENT and Adjudin could become the new long- and short-term choices for men who want to share the responsibility for family planning. 


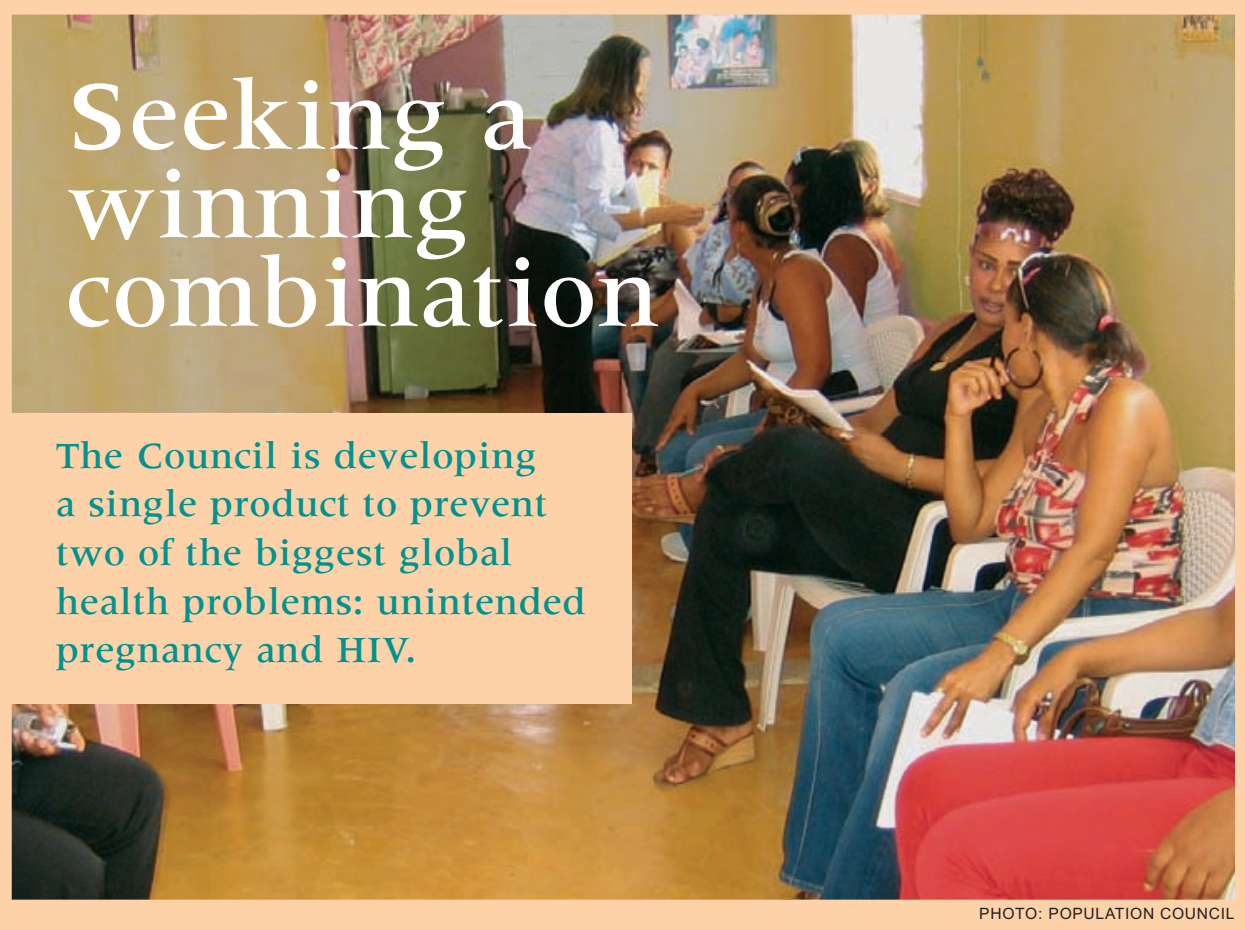

THE PROBLEM Unintended pregnancy is not the only health risk for sexually active people today. HIV and other sexually transmitted infections threaten the lives of millions of people around the world. Condoms are currently the only option women have to protect themselves from both HIV and unwanted pregnancy. However, condom use is notoriously inconsistent and, in some societies, the decision about whether to use a condom is out of the woman's control.

THE PROGRESS The Council is investigating a single product that would prevent both pregnancy and HIV transmission. We are uniquely positioned to conduct this research because of our leadership in devel- oping both contraceptives and microbicides, which are products intended to prevent the transmission of HIV. Combining a microbicide with a contraceptive in one product such as a gel, implant, or vaginal ring would provide reliable treatment for two of today's biggest sexual health concerns.

THE SOLUTION For women who wish to prevent pregnancy and protect against HIV transmission, a product that offers both benefits could provide a cost-effective solution that helps achieve both goals. For people with limited contact with health care professionals and little money, dual-use products might make the difference between illness and health.

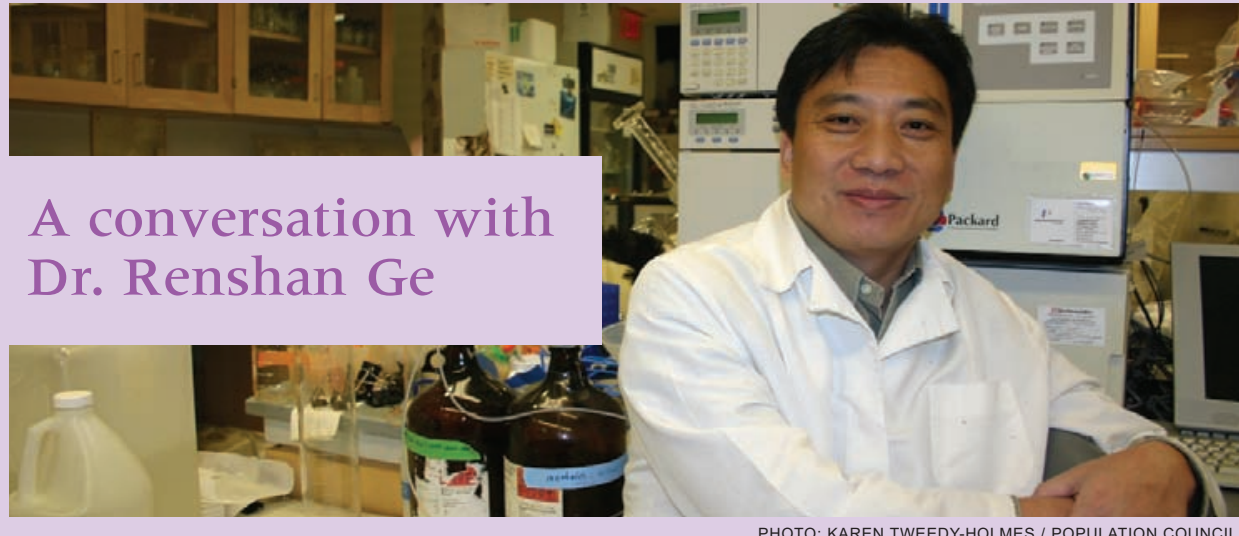

TELL US ABOUT A PROBLEM YOU ARE STUDYING.

One promising project is our research on stem Leydig cells. These are exciting cells, as they are the precursors to fully formed Leydig cells, which produce testosterone. Population Council scientists were the first to discover these stem cells, and we are working hard to understand exactly how they become fully functioning Leydig cells. Knowing exactly how a stem cell changes into a Leydig cell would open new possibilities in controlling male fertility and also provide better treatment for men and boys with inadequate hormone levels and others with decreased fertility. I am proud to be a part of this research.

WHY ARE YOU INTERESTED IN MALE CONTRACEPTION?

I don't think it's fair for women to be the only ones worrying about contraception. The burden of contraception needs to be shared. That's why I started working on gossypol in 1988. Gossypol was the first chemical used for male contraception, but it had serious side effects, like hypertension. I came to the Population Council from China 13 years ago to study these side effects and find ways to prevent them. SCIENTIST?

I guess I knew I was good at science when I was 16 and I won first place in a national competition for math and science back in China.

ARE YOU ABLE TO VISIT CHINA VERY OFTEN?

I visit China every year to see my parents and to help train new scientists in the field. When appropriate, I try to bring these new minds here to work at the Council's Center for Biomedical Research. They add their own perspective to the research and often return to enrich the field in tries to enhance our staff. That's one of my favorite things about working here-the philosophy of collaboration. We work with many other labs and universities to share knowledge and to further the field.
DID YOU ALWAYS WANT TO BE A China. We look to many other coun- 


\section{DONOR PROFILE}

\section{KATY STOKES:}

WHY I GIVE TO

THE COUNCIL

After I finished law school, I spent six months in Kenya doing research on battered women. I was astounded by how many women had lost at least one of their children and were still overburdened with more children than they could support. How could it be that these conditions exist in the 21 st century?

Although I live in America, as a woman, a mother, and someone with my own aspirations and dreams, I identify with the women in Kenya.

My trip to Kenya opened my eyes to the overwhelming heartbreak of mothers and children who die because women have no say in how many children they want. The Population Council is known for research that finds solutions to these tragic and complex problems.

I quickly found many examples of why we cannot just throw money at the problem: boxes of donations that were never opened and shells of buildings that were never used or maintained. I saw charities that were well inten- tioned but came to the country with preconceived ideas about what should work instead

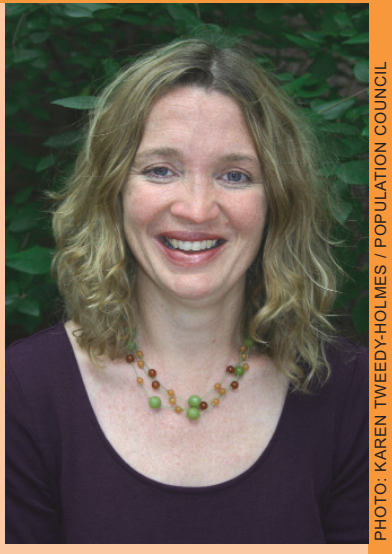

of listening to people on the ground.

This is a big difference about the Population Council. The Council listens to people and provides scientifically tested answers tailored to local situations.

Council researchers understand that the challenges facing women in poverty are complex. Best of all, governments and other large organizations implement programs developed and tested by the Council, multiplying the impact of my donation. To me, that is a smart investment for high-quality research that empowers women everywhere.

I give because I want to send a message to those women in Kenya that they are not alone, that someone else cares. I give to the Population Council because its research leads to huge impact with every dollar.

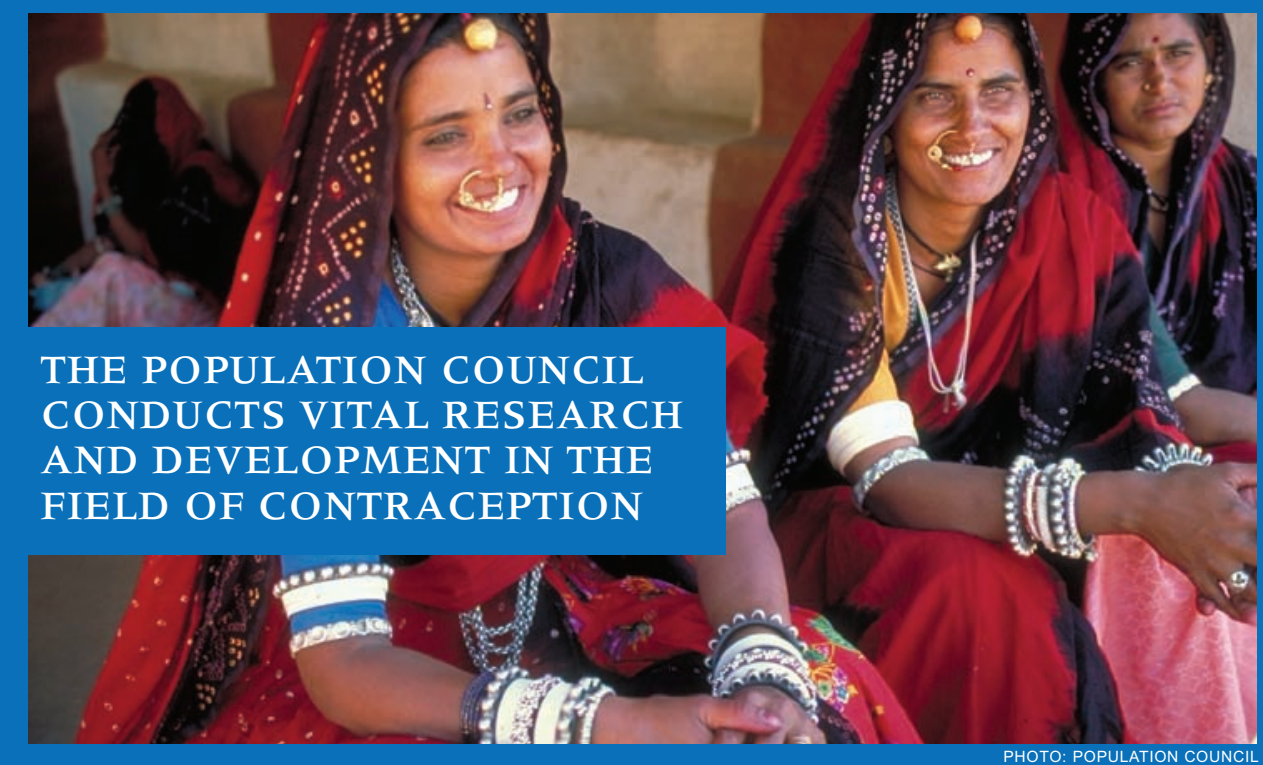

THE COUNCIL IS A LEADER IN THE FIELD OF NEW CONTRACEPTIVE technologies. This issue of Momentum highlights just a few of our achievements and new developments. With your support, we can do even more. Few organizations, public or private, are willing to invest in new contraceptive development. We are one of the few, and that is why your donation is critically important to enable us to continue to develop more contraceptive options for both men and women.

We hope you will join us in our effort to provide women and men with the choices they need to plan their families. Your donation will help us work toward a day when no woman will feel powerless to protect herself from a pregnancy she does not want or cannot support. Few decisions are more personal or important than choosing when and how many children to have. With your help, we are working toward the day when every man and woman can choose a birth control method that gives them control over that decision.

www.popcouncil.org/supporting www.popcouncil.org/publications/momentum

SOURCES FROM INSIDE FRONT COVER: 1,2 Singh, S., J.E. Darroch, M. Vlassoff, and J. Nadeau. 2003. Adding It Up: The Benefits of Investing in Sexual and Reproductive Health Care. New York: Alan Guttmacher Institute (AGI) and It Up: The Benefits of Investing in Sexual and Reproductive Health Care. New York: Alan Guttmacher Institute (AGI)
United Nations Population Fund (UNFPA). Pp. 18-19. ${ }^{3}$ Population Reference Bureau (PRB). 2008. Family Planning Worldwide: 2008 Data Sheet. Washington, DC: PRB. P. 4. ${ }^{4}$ The Alan Guttmacher Institute (AGI). 1999. Sharing Responsibility: Women, Society and Abortion Worldwide. New York: AGI. P. 25. ${ }^{5}$ Daulaire, N., P. Leidl, L. Mackin, et al. 2002. "Promises to Keep: The Toll of Unintended Pregnancies on Women's Lives in the Developing World." Washington, DC: Global Health Council. P. 11. ' Frost, J.J., S. Singh, and L.B. Finer. 2007. “U.S. women's one-year contraceptive use patterns, 2004." Perspectives on sexual and Reproductive Health $39(1):$ : 1. " Glasier, A.F.,
R. Anakwe, D. Everington, et al. 2000. "Would women trust their partners to use a male pill?" Human Reproduction 15(3): 646-649 8 Greene, M.E. and A. F. Biddlecom. 2000. "Absent and problematic men: Demographic accounts 15(3): 646-649. ' Greene, M.E. and A.E. Biddlecom. 2000. “Absent and problematic men: Demographic accounts of male reproductive roles." Population and Development Review 26(1): 94 . 9Population Council. 2008. "Building on factsheets/RH_ContraceptiveDev.pdf.> ${ }^{10}$ Arch Foundation. 2008. First Quarter Operating Report. 6 May. P. 4 